\title{
Fast pyrolysis of tannins from pine bark as a renewable source of catechols
}

\author{
Oscar Pinto ${ }^{\mathrm{a}}$, Romina Romero ${ }^{\mathrm{a}, *}$, Marion Carrier $^{\mathrm{b}}$, Jörn Appelt ${ }^{\mathrm{c}}$, Cristina Segura ${ }^{\mathrm{a}}$ \\ ${ }^{a}$ Technological Development Unit-UDT, Universidad de Concepcion, Cordillera, 2634, 4191996 Box 4051, Coronel, Chile \\ ${ }^{\mathrm{b}}$ RAPSODEE, CNRS UMR 5203, Université de Toulouse, IMT Mines Albi-Carmaux, Campus Jarlard, 81013 Albi CT Cedex 09, France \\ ${ }^{\mathrm{c}}$ Thünen Institute of Wood Research, Haidkrugsweg 1, Hamburg, Germany
}

Keywords:

Condensed tannins

Bark

Fast pyrolysis

Py-GC-MS

Catechols

\section{A B S T R A C T}

Fast pyrolysis of water-insoluble (W-I) tannins-mainly composed of condensed tannins-obtained from Pinus radiata bark methanol-water extraction was carried out in pursuit of a renewable source of high-value chemicals, in particular catechols. Micropyrolysis in an isothermal furnace unit (Py-GC-MS/FID) was performed between 450-600 ${ }^{\circ} \mathrm{C}$. Catechin and W-I tannins were compared to establish thermal degradation behavior between this fraction and its representative monomer constituent. Additionally, W-I tannins were compared with typical sources of renewable phenols such as pine bark and organosolv-lignin in order to highlight its potential. Benchscale experiments of W-I tannins were performed in a fluidized bed reactor between $400-600{ }^{\circ} \mathrm{C}$ to provide information related to yield and concentration of catechols.

The Py-GC-MS/FID results showed that W-I tannins are prolific of catechol and 4-methylcatechol, similar to their most abundant monomer constituent catechin. However, W-I tannins are not only composed of condensed tannins and some substituted polycyclic aromatic hydrocarbons, triterpenes and carbohydrate-derived compounds were detected. The comparison of pyrolysis products among the renewable sources of phenols showed that W-I tannins yielded the highest relative content of catechols while guaiacols and carbohydrate-derived compounds predominated in the composition of lignin and bark products, respectively. The optimal pyrolysis-oil yield for bench scale assays (37 $\mathrm{wt} \%$ ) was found at $550{ }^{\circ} \mathrm{C}$ and maximum yield of both catechol (4.4 $\left.\mathrm{wt} \%\right)$ and 4 methylcatechol $(2.3 \mathrm{wt} \%)$ were also obtained at $550{ }^{\circ} \mathrm{C}$.

\section{Introduction}

Biomass provides a renewable source of chemicals, materials and fuels production [1]. More specifically, significant attention has been given to the recovery of phenolic compounds present in bark pyrolysisoil [2] to substitute petroleum-based chemicals given the high content of polyphenols present in bark [3]. Specifically, Pinus radiata bark, which is a residue of the forestry industry in Chile, contains high levels of polyflavanoids called condensed tannins (12-20 wt\%) [4] that are applied widely in the industry of leather, medicine and formulation of resins adhesives. However, bark is also constituted for cellulose (30-40 wt\%), hemicellulose (12-18 wt\%), lignin (20-35 wt\%) [5] and a low percentage of suberin, cutin and fatty compounds [6-8]. Therefore, its pyrolysis-oil is a complex multiphase fluid with a large number of carbohydrate-derived pyrolysis products, waxy materials, aqueous droplets and other products [9], whose affects both performance and cost of separation and purification of phenolic fraction [10]. Consequently, a pretreatment of bark to isolate tannins is a reasonable solution to improve recovery rates and selectivity of high-value compounds.

Commercial and pilot scale extraction processes of tannins have been developed [11,12]. Two main fractions are obtained from methanol-water extraction process: water-soluble tannins (W-S) and water-insoluble tannins (W-I). W-S tannins have been extensively studied and have long been used for application in phenol-formaldehyde resins $[11,13]$. In contrast, the W-I tannins fraction has received less attention. García et al. [14] characterized this fraction and reported contents in tannins and carbohydrates of $78 \mathrm{wt} \%$ and $3.2 \mathrm{wt} \%$, respectively while the remaining content was not reported.

Condensed tannins derived from Pinus radiata bark are mostly oligomeric or polymeric flavanols formed by linkage of $\mathrm{C}-4$ of one unit with $\mathrm{C}-8$ or $\mathrm{C}-6$ of the next monomeric unit with a low presence of prodelphinidins $[15,16]$. Bocalandro et al.Th reported that principal monomers of condensed tannins in the bark of Pinus radiata are (+)-catechin and (-)-epicatechin [17], which have in common the Bring with a catechol structure [16] (Fig.1).

Given the above, condensed tannins represent a potential source for the production of catechols, which are valuable compounds with a

\footnotetext{
* Corresponding author.

E-mail address: rominaromero@udec.cl (R. Romero).
} 
<smiles>[R]c1cc(C2Oc3cc(O)cc(O)c3CC2O)cc(O)c1O</smiles>

\section{$\mathrm{R}=\mathrm{H}$; Catechin or Epicatechin $\mathrm{R}=\mathrm{OH}$; Gallocatechins or Epigallocatechins}

Fig. 1. Chemical structure of monomer-type of condensed tannins.

broad attention in the last years [18]. Catechols are versatile chemicals that can be used e.g. for the design of binders, inorganic/polymer hybrids materials [19] and as functional materials for use in biomedical fields given its both membrane anchor and antibacterial properties [20,21].

Previous micropyrolysis (Py-GC/MS) studies of condensed tannins isolated from pine bark have shown that catechol (1,2-dihydroxybenzene), 4-methylcatechol (4-methyl-1,2-dihydroxybenzene) and resorcinol (1,3-dihydroxybenzene) are the major thermal decomposition products [22,23]. Case et al. [22] reported the pyrolysis at $500{ }^{\circ} \mathrm{C}$ of W-S and W-I tannins obtained from Pinus radiata bark in a fluidized bed reactor. Both fractions were pre-treated with calcium hydroxide and calcium formate to improve pyrolysis performance. Nevertheless, the addition of both chemicals has a significant effect on the composition of the pyrolysis-oil increasing the selectivity to polycyclic aromatic hydrocarbons (PAHs) over catechols. The results obtained indicates that W-S tannins without pre-treatment have fluidization problems, contrastingly with the W-I tannins behavior. Therefore, this study proposes that W-I tannins without pre-treatment are a suitable material for fast pyrolysis, because it can be fed into the reactor, unlike other phenolic materials as lignin [24] or the W-S tannins.

The present study investigates the fate of polymeric structure of W-I tannins of Pinus radiata bark materials, through analytical and bench scale assays at different pyrolysis temperatures. Furthermore, pyrolysis products of W-I tannins are compared with those from other typical phenolic raw materials; focusing on the potential of condensed tannins in this feedstock as a green and renewable source of catechols.

\section{Material and methods}

\subsection{Feedstocks}

Pinus radiata bark was obtained from forest plantations of Bio-Bío Region (Chile), from 15 to 20 years old trees. The tannins were extracted in a pilot-scale plant described by Berg et al. [11]. The bark was mixed with $75 \mathrm{wt} \%$ methanol/water solution in a $1: 6$ mass/volume ratio and the extraction temperature was $120^{\circ} \mathrm{C}$ treated for $120 \mathrm{~min}$. Two solid fractions were obtained: (1) W-S tannins and (2) W-I tannins, the latter of which was studied here.

Lignin was obtained from wood of Pinus radiata through organosolv method using acetic acid (87\%, technical grade) in a 1:10 mass/volume ratio at $180^{\circ} \mathrm{C}$ for $120 \mathrm{~min}$ [25]. The materials were grounded and sieved to obtain a particle size between $0.6-1.0 \mathrm{~mm}$ and oven-dried at $40{ }^{\circ} \mathrm{C}$ up to $8 \mathrm{wt} \%$. Proximate and ultimate analyses were performed in order to assess the composition of W-I tannins, which was compared with both catechin and untreated bark. The moisture, ash, volatile matter and fixed carbon content were determined according to Matos et al. [26]. The elemental analysis of $\mathrm{C}, \mathrm{H}, \mathrm{N}$ was performed on a Leco
(628 CHN3607, USA) instrument and the oxygen content was calculated by difference. Thermogravimetric analysis (TGA) was performed to determinate the thermal stability of feedstocks (Pinus radiata bark and W-I tannins) and also catechin (CAS number 154-23-4) as reference compound. The TGA was carried out on a NETZSCH TGA instrument (STA 409 PC, Germany). Approximately $6 \mathrm{mg}$ of sample was heated at $5{ }^{\circ} \mathrm{C} \min ^{-1}$ from $20^{\circ} \mathrm{C}$ to $850{ }^{\circ} \mathrm{C}$ under $70 \mathrm{~mL} \mathrm{~min}^{-1}$ of $\mathrm{N}_{2}$ flow ( $\geq 99.999 \%$, Air Liquide).

\subsection{Pyrolysis}

\subsubsection{Pyrolysis-GC-MS/FID}

The volatiles from W-I tannins isolated from Pinus radiata bark and catechin pyrolysis were studied at different temperatures $\left(450^{\circ} \mathrm{C}\right.$, $500{ }^{\circ} \mathrm{C}, 550^{\circ} \mathrm{C}$ and $600{ }^{\circ} \mathrm{C}$ ) in order to compare their primary decomposition products. In parallel, an explorative study of the chemical composition of volatiles from untreated bark, W-I tannins and organosolv-lignin (all obtained from Pinus radiata) was performed at $550{ }^{\circ} \mathrm{C}$ to establish the main differences in the volatile compounds for each phenolic source under the same experimental conditions.

The assays of analytical pyrolysis were carried out in an isothermal micropyrolysis unit (AS-1020E, Frontier Laboratories). This device was coupled to a gas chromatograph (GC, 6890 N GC, Agilent Technologies) with flame ionization detector (GC, $6890 \mathrm{~N} \mathrm{GC}$, Agilent Technologies) and also equipped with a mass spectrometry detector (5975C MSD, Agilent Technologies). Approximately $80 \mu \mathrm{g}$ of the sample was weighted in a microbalance (Excellence Plus XP6 model, Mettler Toledo) and was loaded into the preheated furnace using an auto-shot sampler in the micropyrolysis unit. A heating rate of $2000^{\circ} \mathrm{C} \mathrm{s}^{-1}$ was applied until reaching the pyrolysis temperature under a helium flow of $1.00 \mathrm{~mL} \mathrm{~min}^{-1}$. Volatile compounds were separated and analyzed with a GC-MS/FID system using a VF-1701 column (length $60 \mathrm{~m}$; internal diameter $0.25 \mathrm{~mm}$; film thickness $0.25 \mu \mathrm{m}$, Agilent Technologies, USA). The injector and detector temperatures were kept at $250^{\circ} \mathrm{C}$ and $280^{\circ} \mathrm{C}$, respectively. The initial GC oven temperature was $45^{\circ} \mathrm{C}$, which was held for $4 \mathrm{~min}$ before heating to $280^{\circ} \mathrm{C}$ at $3^{\circ} \mathrm{C} \mathrm{min}{ }^{-1}$. The final temperature was maintained for $40 \mathrm{~min} \mathrm{~A}$ split ratio of $15: 1$ was set for injection. The Py-GC/MS technique could not give a quantitative analysis of detected compounds, but can provide a semi-quantitative analysis based on the relative content of each compound. According to the peak area (\%) of compounds detected by the mass selective detector in the pyrolysate, the average values and corresponding standard deviation of peak area for each identified compound were calculated and used for interpretation [27]. Peak identification was achieved by combining the MassFinder 4 software and NIST (2014) mass spectral library. Posteriorly, the identified compounds were grouped on the basis of their main functional group; and the relative content of each group compounds was determined as a percentage of total identified peak area. The identified compounds were categorized into seven categories: phenol-type compounds, catechol-type compounds, carbohydrate-derived compounds (anhydrosugars and pyrans/furans), benzenes (e.g. benzenes and PAHs derives), lipophilic extractives (including terpenes, terpenoids, medium and long-chain fatty acids and long-chain hydrocarbons) [28], methoxyphenols (guaiacols-type) and short-chain acids such as acetic acid.

\subsection{Fast pyrolysis}

Temperature effect over the yield of catechols was studied for W-I tannins pyrolysis. The temperature range studied was bounded between $400{ }^{\circ} \mathrm{C}$ and $600{ }^{\circ} \mathrm{C}$. Fast pyrolysis experiments were carried out in a bench-scale system described in Moore et al. [29]. W-I tannins were dosed through a screw feeder and then pneumatically transported into the reactor, which measured $32.5 \mathrm{~cm}$ of length and $4.8 \mathrm{~cm}$ of inner diameter, using a nitrogen flow rate of $6 \mathrm{~L} \mathrm{~min}^{-1}$ (Normal Temperature and Pressure, NTP). Quartz sand (30-50 mesh) was used as fluidized 
bed material. Nitrogen was used as a gas carrier ( $9 \mathrm{~L} \mathrm{~min}{ }^{-1}$, NTP). The hot gas filter was maintained at $400{ }^{\circ} \mathrm{C}$. The residence time of vapors, calculated as described by Scott et al. [30], was $\leq 1.0 \mathrm{~s}$ and $\leq 2.6 \mathrm{~s}$ for the reactor and the hot zone (reactor + hot gas filter), respectively. The vapors/aerosols were cooled and collected in a condenser at $15^{\circ} \mathrm{C}$ followed by an electrostatic precipitator (ESP). The pyrolysis products retained in the reactor, hot gas filter, condenser and ESP were collected, weighed and kept separately for further analyses. Gravimetric mass balance (XB 3200C, Precisa) was established based on biochar collected from both reactor and hot-gas filter, pyrolysis-oil (organic liquid + water) collected from both condenser and ESP, and the gas was calculated by difference.

\subsection{Pyrolysis-oil characterization}

Pyrolysis-oil fractions-ESP fraction and the aqueous fraction (recollected from condenser)-were both characterized independently. Their water content was determined using a Mettler Toledo V20 volumetric KF titrator (ASTM E871) using volumetric Karl-Fischer titration (Merck). The aqueous fraction was lyophilized in order to remove the high water content and solubilized again in acetone p.a. (99.8\%, Merck) previous to the GC analyses.

Compound identification of both condensates was done by GC/MS (Model HP 6890 Series, Agilent Technologies) with the same conditions used for Py-GC/MS-FID. Data were processed with a Hewlett-Packard Chemstation and the peak identification was guided by the NIST (2014) mass spectral library. Additionally, catechol, 4-methylcatechol, guaiacol, $p$-cresol and phenol were quantified through a GC-flame ionization. The GC/FID system (7820 A model, Agilent Technologies) was equipped with HP-5 column (length $30 \mathrm{~m}$; internal diameter $0.32 \mathrm{~mm}$; film thickness $0.25 \mu \mathrm{m}$, Agilent Technologies, USA). The initial GC oven temperature was $40^{\circ} \mathrm{C}$, which was held for $1 \mathrm{~min}$, then it was heating up to $180^{\circ} \mathrm{C}$ at $5^{\circ} \mathrm{C} \mathrm{min}{ }^{-1}$ and it was held for $2 \mathrm{~min}$. After, was heated to $280^{\circ} \mathrm{C}$ at $15^{\circ} \mathrm{C} \mathrm{min}^{-1}$, and the final temperature was maintained for $20 \mathrm{~min}$. Helium was used as carrier gas at $1.5 \mathrm{~mL} \mathrm{~min}^{-1}$. The quantification was performed using calibration curves from analytical standards for phenol (99\%, Merck), p-cresol (4-methylphenol) (98\%, Merck), guaiacol (2-methoxyphenol) (98\%, Merck), catechol (1,2-dihydroxybenzene) (99\%, Sigma-Aldrich) and 4-methylcatechol (4-methyl-1,2-dihydroxybenzene) (95\%, Sigma Aldrich). Detection of polar compounds such as acids or carbohydrate-derived compounds was performed on a high-performance liquid chromatography (HPLC) with refractive index detection in a Shimadzu HPLC system equipped with two equal columns: Rezex ${ }^{\mathrm{mm}}$ ROA-Organic Acid $\mathrm{H}^{+}$(8\%), 300 x $7.80 \mathrm{~mm}$ (Phenomenex, USA). The analysis was performed according to Müller et al. for aqueous pyrolysis-oil fraction [31].

\section{Results and discussion}

\subsection{Elemental composition and thermal behavior of water-insoluble tannins}

The W-I tannins have a low inorganic content of $0.23 \mathrm{wt} \%$, volatile matter up to $64.82 \mathrm{wt} \%$ and fixed carbon of $34.96 \mathrm{wt} \%$ (Table 1). Catechin and W-I tannins have a similar elemental formula with a slightly higher hydrogen content in the latter. This suggests that extraction process of condensed tannins from Pinus radiata bark does not modify their general chemical composition. Actually, W-I tannins and catechin have an $\mathrm{O} / \mathrm{C}$ ratio of 0.46 and 0.48 while $\mathrm{H} / \mathrm{C}$ ratios are 0.097 and 0.080 , respectively. In contrast, bark has a low carbon content that it entails a higher $\mathrm{O} / \mathrm{C}$ ratio of 0.68 . Moreover, the chemical composition of bark and W-I tannins is similar to reported in literature [22,32].

The thermal behavior of the three materials is remarkably different (Fig. 2). Catechin has a noticeably degradation peak at $285^{\circ} \mathrm{C}$ due to the breakdown of the weakest $\mathrm{C}-\mathrm{C}$ bond between B-ring and C-ring and thus the liberation of B-ring compounds (Fig. 1) [33]. Then, catechin has a slow decomposition rate and a total weight loss of $51 \%$ is reached at
Table 1

Proximate and ultimate analysis of catechin, W-I tannins and untreated bark.

\begin{tabular}{|c|c|c|c|}
\hline & Catechin & W-I tannins & Bark \\
\hline Moisture & $2.70 \pm 0.10$ & $7.89 \pm 0.11$ & $8.62 \pm 0.03$ \\
\hline \multicolumn{4}{|c|}{ Proximate analysis $(\mathrm{db}, \mathrm{wt} \%)$} \\
\hline Ash & $0.07 \pm 0.10$ & $0.23 \pm 0.01$ & $0.91 \pm 0.02$ \\
\hline Volatile matter & $71.41 \pm 0.85$ & $64.82 \pm 0.74$ & $71.57 \pm 0.42$ \\
\hline Fixed carbon $^{\mathrm{a}}$ & $28.51 \pm 0.95$ & $34.96 \pm 0.75$ & $27.51 \pm 0.44$ \\
\hline \multicolumn{4}{|c|}{ Ultimate analysis (daf, wt\%) } \\
\hline $\mathrm{C}$ & $63.8 \pm 0.2$ & $63.9 \pm 0.9$ & $55.8 \pm 0.1$ \\
\hline $\mathrm{H}$ & $5.1 \pm 0.03$ & $6.2 \pm 0.2$ & $5.5 \pm 0.1$ \\
\hline $\mathrm{N}$ & $0 \pm 0.10$ & $0 \pm 1.0$ & $0 \pm 0.4$ \\
\hline $\mathrm{O}^{\mathrm{a}}$ & $31.0 \pm 0.2$ & $29.7 \pm 0.8$ & $37.8 \pm 0.6$ \\
\hline Chemical formula & $\mathrm{C}_{15} \mathrm{H}_{14.4} \mathrm{O}_{5.4}$ & $\mathrm{C}_{15} \mathrm{H}_{17.5} \mathrm{O}_{5.4}$ & $\mathrm{C}_{13.0} \mathrm{H}_{15.6} \mathrm{O}_{6.8}$ \\
\hline
\end{tabular}

a By difference; db: dry basis; daf: dry and ash-free.

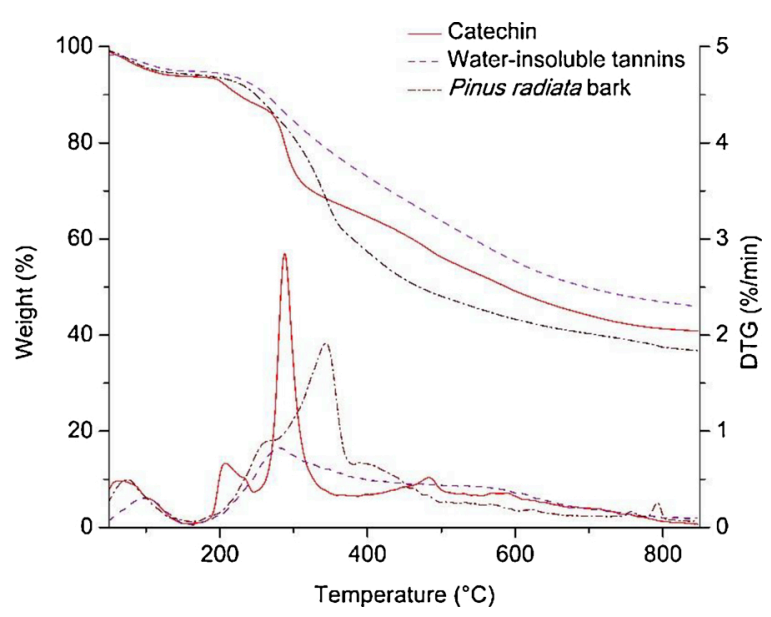

Fig. 2. TGA and DTG curves for catechin, W-I tannins and Pinus radiata bark. Heating rate $5^{\circ} \mathrm{C} \mathrm{min}^{-1}$.

$800{ }^{\circ} \mathrm{C}$. Meanwhile, W-I tannins have a slow decomposition trend over all temperature range and only a tenuous peak at the same temperature that catechin is observed (close to $280^{\circ} \mathrm{C}$ ), and on the same way that condensed tannins studied for Gaugler et al. [34]. W-I tannins lost up to $20 \mathrm{wt} \%$ between $200-330^{\circ} \mathrm{C}$, after which there was a gradual decrease in sample weight on further heating which led to the total weight loss of $53 \mathrm{wt} \%$ at $800^{\circ} \mathrm{C}$. This differences between W-I tannins and its representative monomer constituent could be explained by recombination reactions on W-I tannins between the polyphenols units linked between them, which are in favor of the formation of a stable aromatic-like structure as another phenolic materials such as lignin [35,36]. On other hand, bark displays a broad temperature degradation profile with an increased decomposition rate between $200-400{ }^{\circ} \mathrm{C}$ due to the heterogeneous chemical structure of pine bark. A shoulder is observed between $250-285^{\circ} \mathrm{C}$ with a similar profile but earlier than W-I tannins. This earlier onset was also observed in Gaugler et al [34]. When they compared pine bark extract of purified condensed tannins with a carbohydrate-rich extract. This shoulder is followed for a little plateau and then the higher peak is observed around $350^{\circ} \mathrm{C}$. This peak coincides with the degradation peak of cellulose according to Shen et al. [37], which is the principal constituent of pine bark (30-40 wt\%) [5]. These two differences between bark and W-I tannins reveal a low carbohydrate content in the latter in agreement with the characterization of Garcia et al. [14]. Subsequently, this point is relevant for fractionation of phenolic compounds obtained from W-I tannins pyrolysis products.

\subsection{Pyrolysis-GC-MS/FID}

a) Temperature effect on pyrolysis products behavior of W-I tannins vs catechin 
Table 2

Relative distribution of volatiles compounds groups produced during the micropyrolysis (Py-GC/MS) of catechin and W-I tannins at different temperatures.

\begin{tabular}{|c|c|c|c|c|c|c|c|c|}
\hline \multirow{2}{*}{$\begin{array}{l}\text { Relative content* } \\
(\%)\end{array}$} & \multicolumn{4}{|c|}{ Catechin } & \multicolumn{4}{|c|}{ W-I tannins } \\
\hline & $450^{\circ} \mathrm{C}$ & $500{ }^{\circ} \mathrm{C}$ & $550^{\circ} \mathrm{C}$ & $600^{\circ} \mathrm{C}$ & $450^{\circ} \mathrm{C}$ & $500{ }^{\circ} \mathrm{C}$ & $550^{\circ} \mathrm{C}$ & $600{ }^{\circ} \mathrm{C}$ \\
\hline Catechols & 48.2 & 40.1 & 33.6 & 32.0 & 33.2 & 33.0 & 32.2 & 33.9 \\
\hline Phenols & 25.0 & 31.4 & 36.0 & 38.2 & 9.21 & 8.93 & 9.24 & 7.82 \\
\hline Methoxyphenols & N.D. & N.D. & N.D. & N.D. & 15.9 & 13.3 & 13.4 & 12.1 \\
\hline Benzenes & 9.00 & 8.71 & 8.89 & 7.81 & 8.06 & 7.97 & 9.06 & 7.32 \\
\hline Acids & 17.6 & 19.6 & 21.9 & 21.7 & 1.21 & 1.41 & 1.35 & 1.33 \\
\hline Carbohydrate-derived & 0.30 & 0.30 & 0.60 & 0.30 & 5.66 & 5.86 & 6.11 & 4.11 \\
\hline Lipophilic extractives & N.D. & N.D. & N.D. & N.D. & 26.8 & 29.5 & 28.6 & 33.4 \\
\hline Total & 100.0 & 100.0 & 100.0 & 100.0 & 100.0 & 100.0 & 100.0 & 100.0 \\
\hline
\end{tabular}

N.D: Not detected; *Content relative to total chromatographic area of the pyrolysate.
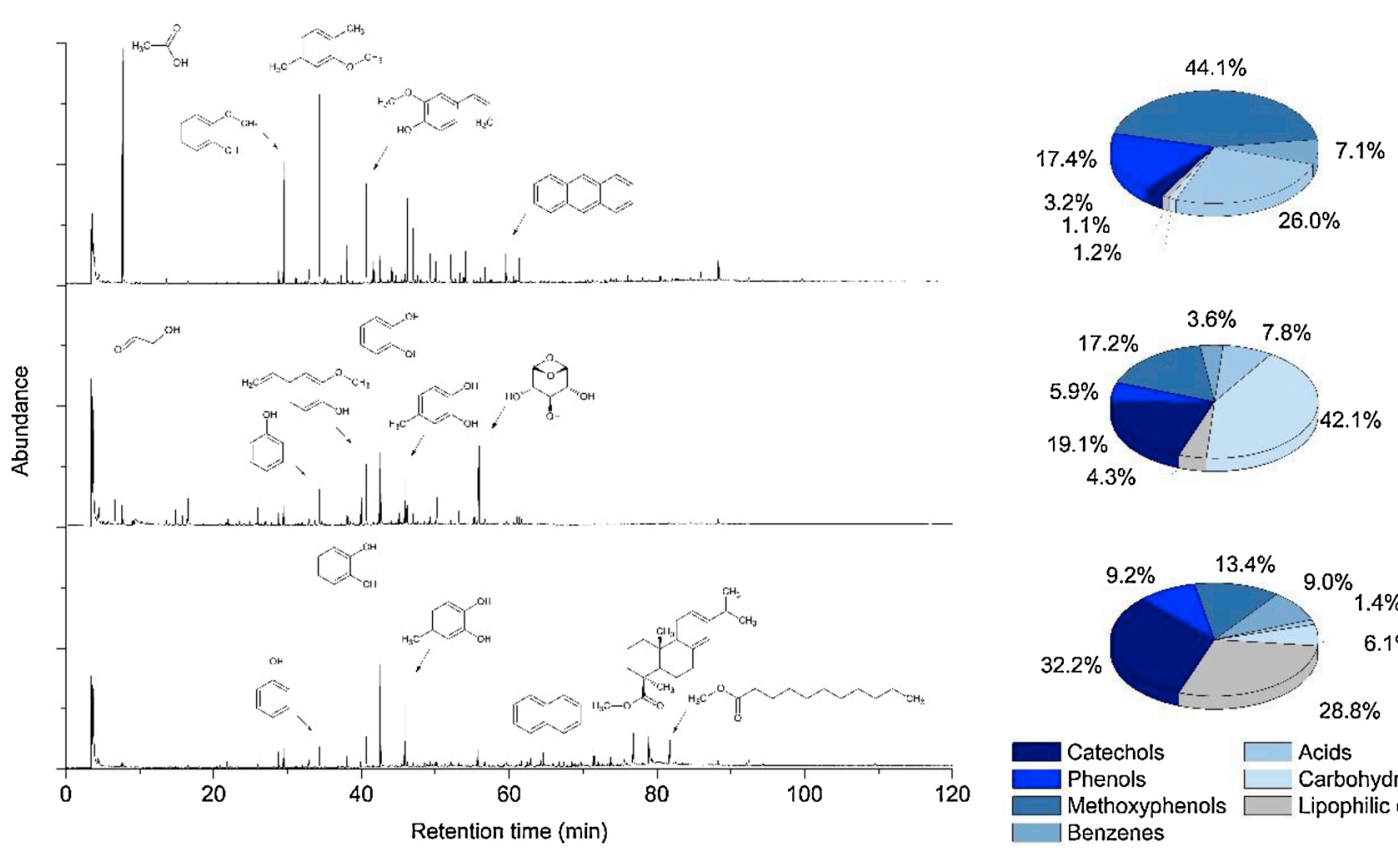

B)

C)

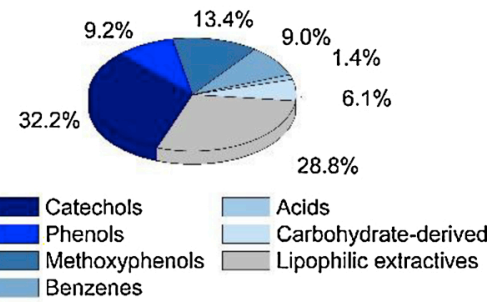

Fig. 3. Chromatograms and relative product distribution for Py-GC-MS/FID at $550{ }^{\circ} \mathrm{C}$ of A) organosolv lignin, B) untreated bark and C) W-I tannins of Pinus radiata bark.

The identified pyrolysis products of the W-I tannins and catechin were semi-quantified through area percentage to establish a thermal behavior study of W-I tannins. The results are presented in Table 2 and the chromatograms of W-I tannins and catechin only at $550{ }^{\circ} \mathrm{C}$ were included in the Supplementary Material. The main detected products of both materials are B-ring products (catechol and 4-methylcatechol). Catechol is more abundant than 4-methylcatechol which suggests that breaking of the $\mathrm{C} 2-\mathrm{C}^{\prime}$ ' bond between the $\mathrm{B}$ and $\mathrm{C}$ rings is more prolific than C-ring fission (Fig. 1) [23]. A remarkable amount of phloroglucinol (1,3,5-benzenetriol), derived product from the A-ring decomposition [33], was observed during catechin pyrolysis, whereas this compound was not detected for W-I tannins. The non-detection of phloroglucinol for W-I tannins can be explained by the influence of C4-C8 and C4-C6 intermonomeric linkages during the charring process of the A-ring in condensed tannins forming non-volatile compounds and preventing the formation of this compound [33,42]. As previously was stated, tannins from Pinus radiata bark are mainly composed by dihydroxy-B-rings (procyanidic rings, catechol-type), although a minor portion may well contain prodelphinidin B-rings with a pyrogallol structure [15], and this difference may affect the release of catechol through dehydroxylation of pyrogallol to catechol of the B-ring.

Regarding to thermal trends, the increase of pyrolysis temperature (from $450^{\circ} \mathrm{C}$ to $600{ }^{\circ} \mathrm{C}$ ) caused that the relative proportions of catechols formed from catechin decline from 48 to $32 \%$ (Table 2). In contrast, phenol increased from $25 \%$ to $38 \%$. This suggests that phenol formation could be favored at the expense of catechols production with the temperature increase according to the mechanism proposed for Lomnicki et al. [38]. In addition, the steady increase in benzene release indicates that production of PAHs remains limited in comparison to higher temperatures $\left(>600{ }^{\circ} \mathrm{C}\right.$ ) [38]. In the case of W-I tannins, the pyrolysis temperature between $450^{\circ} \mathrm{C}$ and $600^{\circ} \mathrm{C}$ does not play a significant role in the production of catechols (Table 2). MoMoreover, the presence of methoxyphenols was detected and their relative content decreased at higher temperatures. This is in agreement with a study whose reported similar temperature effect on the thermoconversion of lignin [39]. The thermal stability of $-\mathrm{O}-\mathrm{CH}_{3}$ bond is lower than $-\mathrm{OH}$ bond, which could explain the early decomposition of methoxyphenols [40].

Finally, in W-I tannins were detected compounds derives from lipophilic extractives which is the main difference between W-I tannins and catechin, and these could be the principal impurity in the green production of catechols from condensed tannins. This detection of terpene-derived could be attributed to thermal decomposition of resin acids and diterpenoids of the suberin derivatives from pine bark [28]. In the case of catechin, the different grouped compounds have a tendency thermal decomposition regarding temperature variation (Table 2); however, for W-I tannins, this behavior is not clear and is not possible to identify the temperature effect on their thermal decomposition.

b) Phenolic-rich materials evaluation

To underline the high-value potential of W-I tannins as source of 
catechols, a comparison with the micropyrolysis products distribution from untreated bark and softwood lignin was carried out at $550{ }^{\circ} \mathrm{C}$. The Fig. 3 shows the primary decomposition products revealing meaningful thermal and structural differences in the feedstocks. Untreated bark (Pinus radiata) was converted primarily in carbohydrate-derived compounds (42.1\%), catechols (19.1\%) and methoxyphenols $(17.2 \%)$ (Fig. 3B), which could respectively come from the thermal degradation of cellulose and hemicelluloses, polyflavanoids and lignin, according to the classic review of biomass pyrolysis routes [41] and mechanisms proposed for the pyrolysis of condensed tannins [23,42].

The primary decomposition of softwood lignin (Pinus radiata) produced a large portion of methoxyphenols (44.1\%) and phenols (17.4\%) (Fig. 3A) released from the pyrolysis of coniferyl alcohol, which is the predominately unit in softwood lignin [43]. However, a low content of catechols was observed (3.2\%) in softwood lignin. Therefore, the transformation of W-I tannins displayed a catechol portion noticeably larger, up to $32.2 \%$, than untreated bark and softwood lignin (Table 2).

The potential of W-I tannins as source of catechols becomes interesting due to the low content of carbohydrate-derived compounds whereas in bark is one of the major constituents, limiting the phenolic compounds extraction [44]. However, the W-I tannins matrix is composed of an important fraction of lipophilic extractives. The major constituents of lipophilic group are given by terpenes (diterpenes, triterpenes and resin acids), long chains of alkyl, ester and fatty compounds. Up to $29 \%$ of lipophilic compounds were detected in W-I tannins against $4.34 \%$ for untreated bark. This difference is given by the earlier carbohydrate-derived extraction from the bark, therefore, the relative content of the lipophilic compounds in W-I tannins is mathematically increased in the total ion area of the pyrolysate. These lipophilic compounds were identified in a previous work by Weston [6] from Pinus radiata bark through conventional extraction methods.

\subsection{Fast pyrolysis of water-insoluble tannins}

A number of technical issues are usually encountered when processing phenolic raw materials [22,24,29,45]. Indeed, the formation of agglomerates due to the softening behavior of lignin led to feeding and fluidization problems. In contrast, the processing of W-I tannins through fast pyrolysis in a fluidized bed reactor does not show these clogging issues, which favors the fluidized-bed method in combination with the use of W-I tannins as an alternative production of phenolic chemicals.

In this study, the products yield trends established from mass balances of W-I tannins fast pyrolysis at different temperatures confirm the classic and critical role of temperature. The Fig. 4 shows a decreasing solid yield trend from 60 to $34 \mathrm{wt} \%$ as temperature increases from $400{ }^{\circ} \mathrm{C}$ to $600^{\circ} \mathrm{C}$ A higher amount of char was generated at low temperatures when compared to those reported for bark [32] or pine wood [29]. This behavior is in accordance with the TGA results discussed previously, which showed high dispositions to char formation. Similar trends have been reported for pyrolysis of lignin indicating significantly reduced pyrolysis-oil yield in favor to the formation of char with values nearby to $40 \mathrm{wt} \%$ at $530{ }^{\circ} \mathrm{C}$ [29]. The whole pyrolysis-oil reached the highest yield of $37 \mathrm{wt} \%$ at an intermediate temperature of $550^{\circ} \mathrm{C}$ (Fig. 4). In contrast, the organic liquid yield increased from 16 to $29 \mathrm{wt} \%$ as increasing temperature from $400{ }^{\circ} \mathrm{C}$ to $550{ }^{\circ} \mathrm{C}$ and remained almost stable when the pyrolysis temperature was increased to $600{ }^{\circ} \mathrm{C}$. This difference between trends is mainly due to the fact that the overall pyrolysis-oil contains a large water fraction $\left(15-20 \mathrm{wt} \%\right.$ over pyrolysis-oil content) until $550^{\circ} \mathrm{C}$, level that dropped drastically to $8 \mathrm{wt} \%$ when carrying out the fast pyrolysis at $600{ }^{\circ} \mathrm{C}$; suggesting an important change in chemistry with a higher production of non-condensable gases.

\subsection{Pyrolysis-oil characterization and yield of catechols}

Differences on the chemical composition of the collected liquid

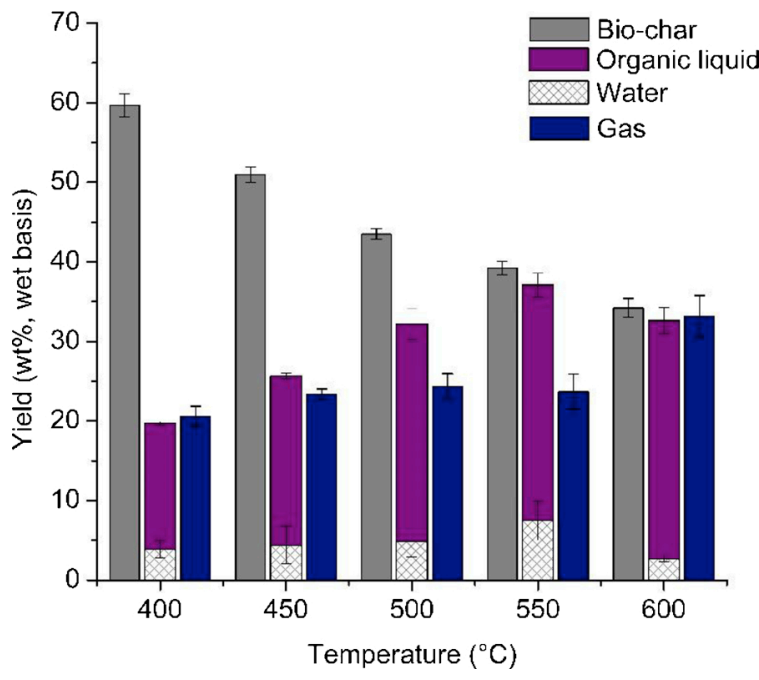

Fig. 4. Temperature effect on product distribution from the pyrolysis of W-I tannins in bench scale (error lines indicate standard deviation).

fractions (i.e., aqueous and ESP fractions) can be observed from Fig. 5. The ESP fraction (Fig. 5A) presents a broad range of organic compounds such as catechols, phenols and methoxyphenols, principally. Catechols constitute the largest portion, which is in accordance with the previous micropyrolysis assays performed. Other chemical groups such as PAHs, terpenes (diterpenes, triterpenes and resin acids), alkyl compounds, fatty compounds and long-chain esters (See Supplementary Material for further details) were identified, as well as, for micropyrolysis assays discussed previously. However, a major effort should be done for characterization and quantification of all these compounds, whose cannot be detected by gas-chromatography technique without pretreatment or derivatization. Besides, it is necessary to determine their role in the isolation of catechols.

The chemical composition of the aqueous fraction (Fig. 5B) reveals the presence of catechols, phenols and methoxyphenols as well, in addition to some carbohydrate-derived compounds such as levoglucosan. HPLC analyses confirm the presence of acetic acid, levoglucosan, glyoxal and acetol (Supplementary Material). In the untreated bark, acetic acid is systematically reported as one of the main products. However, in the case of W-I tannins, is suspected to be formed when the acetyl groups (dominant substituent groups of the polyphenolic compounds) are released $[29,35]$; but also could be a side product from the C-ring decomposition [33]. The low concentrations of levoglucosan or furfurals in pyrolysis-oil fractions is consequential from the low carbohydrate content in W-I tannins (3.2 wt\%) [14]. This could be beneficial to the recovery rates and improves the isolation of catechols from pyrolysis-oil given the difficulty of their separation [44]. In addition, the low content in carbohydrate-derived compounds could limit the aging of pyrolysis-oils [46].

The phenolic compounds, and especially catechol and 4-methylcatechol, displayed the highest concentrations within the pyrolysis-oil through the whole degradation temperature range (Fig. 6). Concentrations in catechol and 4-methylcatechol reached a maximum of $10.9 \mathrm{wt} \%$ and $5.6 \mathrm{wt} \%$ at $550{ }^{\circ} \mathrm{C}$, respectively, while softwood lignin products were scarce. The substantial decreased observed for those concentrations from $600^{\circ} \mathrm{C}$ could be explained by the cracking of those compounds $[38,40]$. The concentration of catechol compounds in pyrolysis-oil remained quite constant over the temperature range of $400-550^{\circ} \mathrm{C}$; this was not the case for the yields. Fig. $6 \mathrm{~B}$ shows the influence of the pyrolysis temperature in yields of catechol and 4-methylcatechol. Indeed, respective yield of catechol and 4-methylcatechol increased steadily from $2.3 \mathrm{wt} \%$ and $1.1 \mathrm{wt} \%$ at $400{ }^{\circ} \mathrm{C}$ up to $4.4 \mathrm{wt} \%$ and $2.3 \mathrm{wt} \%$ at $550{ }^{\circ} \mathrm{C}$. Over this temperature, the yield of these compounds varied considerably and in the same trend line of pyrolysis-oil 


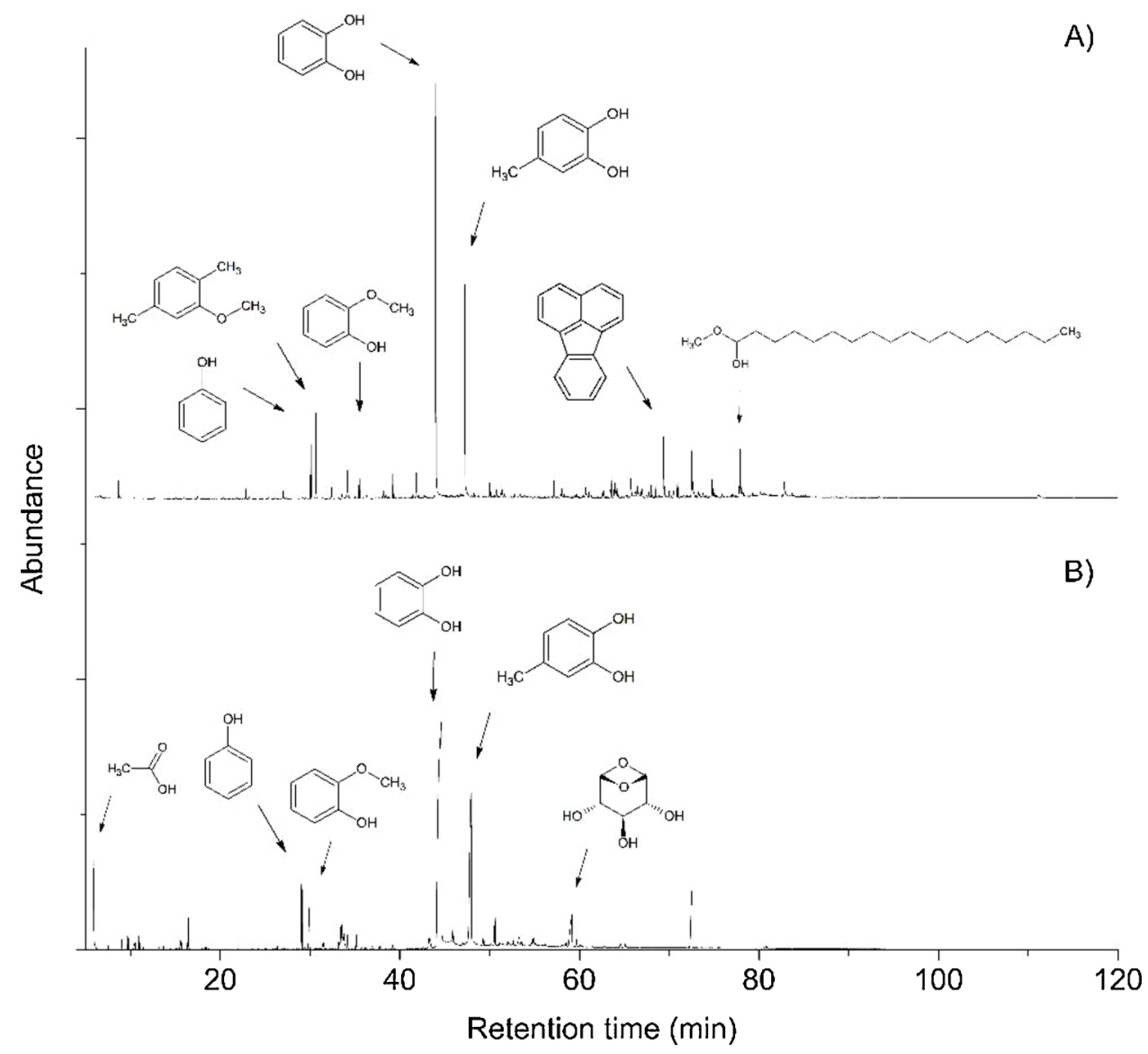

Fig. 5. Total ion chromatograms of W-I tannins pyrolysis-oil produced at $550{ }^{\circ} \mathrm{C}$ : A) ESP (electrostatic precipitator) fraction and $\mathrm{B}$ ) aqueous fraction.

yields (Fig. 4). Therefore, when comparing data shown in Fig. 6 it can be concluded that temperature has an influence on the pyrolysis-oil yield and consequently in catechols yield; however, it does not have a significant influence on the catechols concentration in pyrolysis-oil.

\section{Conclusions}

As in pyrolysis of catechin, the primary pyrolysis products of W-I tannins are mainly catechol and 4-methylcatechol. W-I tannins of Pinus radiata are more prolific of catechols upon pyrolysis than lignin and untreated bark from the same feedstock. The potential of W-I tannins as source of catechols becomes interesting due to the low content of carbohydrate-derived compounds whereas in bark is one of the major constituents, limiting the phenolic compounds extraction. However, lipophilic extractives such as alkyl compounds, triterpenes and resin acids were also identified as an important fraction of W-I tannins pyrolysis products. This reveals less-polar compounds in the matrix of W-I tannins carried over from pine bark extraction and it is necessary to
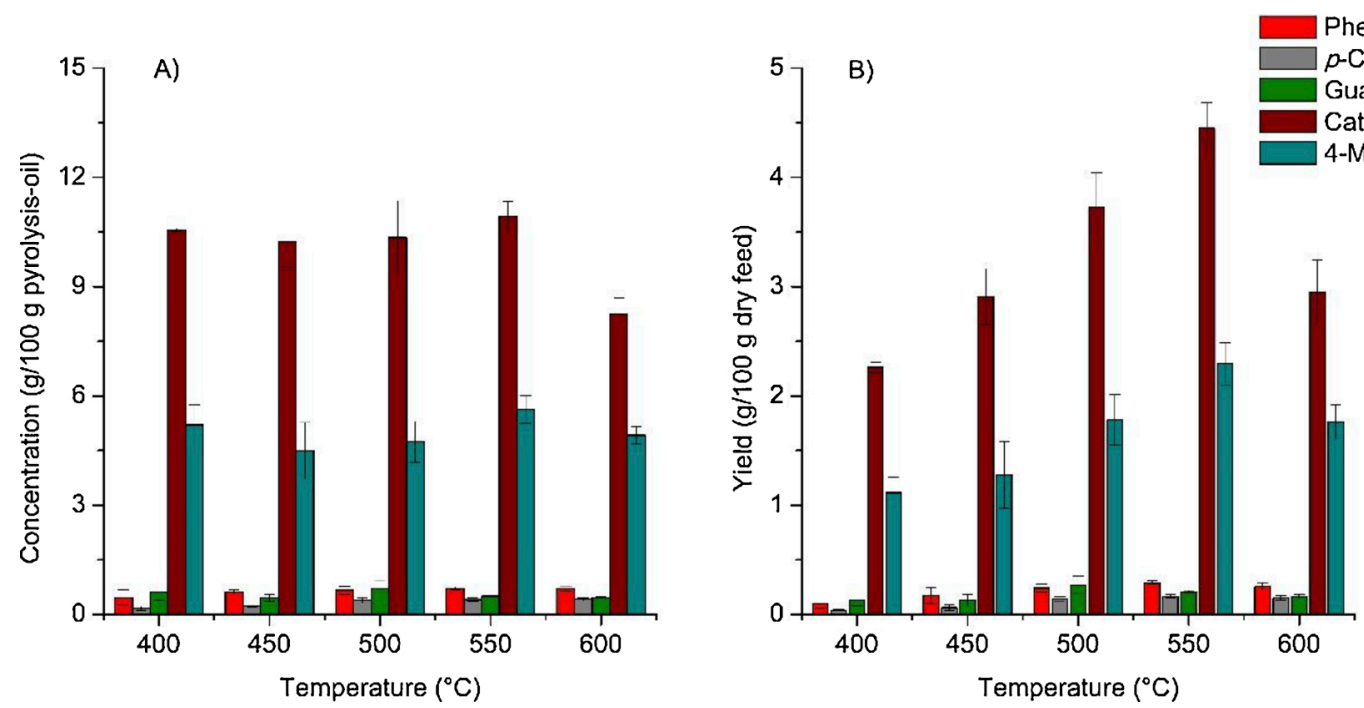

Fig. 6. Temperature effect on A) concentration and B) yield of monophenols for bench scale assays (error lines indicate standard deviation). 
determine their role in the isolation of catechols from pyrolysis-oil.

Bench scale assays for W-I tannins did not show clogging issues or agglomerates in the fluidized-bed reactor. The conversion of this feedstock produced a phenolic-rich pyrolysis-oil with a low content of carbohydrate-derived compounds. Two fractions were obtained: ESP and aqueous. Catechols constitute the largest portion in both fractions, which is in accordance with the previous W-I tannins micropyrolysis assays performed. However, the main difference established between these fractions was the high-molecular weight compounds detected in the ESP fraction. The temperature has an influence on the pyrolysis-oil yield and consequently on catechols yield; however, it does not have a significant influence on the catechols concentration in pyrolysis-oil. Moreover, catechol and 4-methylcatechol reached the highest yields (4.4 and $2.3 \mathrm{wt} \%$ ) at $550{ }^{\circ} \mathrm{C}$.

\section{Acknowledgments}

This research was supported by INNOVA Chile (Grant No. 14IDL230128) and CONICYT PIA/APOYO CCTE AFB170007. The authors thank Patricia Olivera and Lilian Suarez for carrying out part of the experimental and analytical work. Also, they are deeply grateful for the insightful comments of the reviewers.

\section{Appendix A. Supplementary data}

Supplementary material related to this article can be found, in the online version, at doi:https://doi.org/10.1016/j.jaap.2018.10.022.

\section{References}

[1] A.V. Bridgwater, Renewable fuels and chemicals by thermal processing of biomass, Chem. Eng. J. 91 (2003) 87-102, https://doi.org/10.1016/S1385-8947(02) 00142-0.

[2] L.F. Žilnik, A. Jazbinšek, Recovery of renewable phenolic fraction from pyrolysis oil, Sep. Purif. Technol. 86 (2012) 157-170, https://doi.org/10.1016/j.seppur. 2011.10.040.

[3] S. Feng, S. Cheng, Z. Yuan, M. Leitch, C. Xu, Valorization of bark for chemicals and materials: a review, Renew. Sustain. Energy Rev. 26 (2013) 560-578, https://doi. org /10.1016/j.rser.2013.06.024.

[4] D.E. García, W.G. Glasser, A. Pizzi, S.P. Paczkowski, M.P. Laborie, Modification of condensed tannins: from polyphenol chemistry to materials engineering, New. J. Chem. 40 (2016) 36-49, https://doi.org/10.1039/C5NJ02131F.

[5] C. Moya-Villablanca, R. Oses-Pedraza, H. Poblete-Wilson, L. Valenzuela-Hurtado, Efectos del contenido de harina de corteza y madera de Pinus radiata sobre la biodegradación acelerada de compuestos madera-plástico, Maderas. Cienc. y Tecnol. 16 (2014), https://doi.org/10.4067/S0718-221X2014005000004.

[6] R.J. Weston, Neutral extractives from Pinus radiata bark, Aust. J. Chem. 26 (1973) 2729-2734, https://doi.org/10.1071/CH9732729.

[7] A.H. Conner, B.A. Nagasampagi, J.W. Rowe, Terpenoid and other extractives of western white pine bark, Phytochemistry 19 (1980) 1121-1131, https://doi.org/ 10.1016/0031-9422(80)83068-8.

[8] T. Masendra, K. Ashitani, G. Takahashi, Lukmandaru, Lipophilic extractives of the inner and outer barks from six different Pinus species grown in Indonesia, J. For. Res. (2017) 1-8, https://doi.org/10.1007/s11676-017-0545-x.

[9] L. Ingram, D. Mohan, M. Bricka, P. Steele, D. Strobel, D. Crocker, B. Mitchell, J. Mohammad, K. Cantrell, C.U. Pittman, Pyrolysis of wood and bark in an auger reactor: physical properties and chemical analysis of the produced bio-oils, Energy Fuels 22 (2008) 614-625, https://doi.org/10.1021/ef700335k.

[10] D. Wang, D. Li, Y. Liu, D. Lv, Y. Ye, S. Zhu, B. Zhang, Study of a new complex method for extraction of phenolic compounds from bio-oils, Sep. Purif. Technol. 134 (2014) 132-138, https://doi.org/10.1016/j.seppur.2014.07.033.

[11] A. Berg, L. Olave, P. Navarrete, Process for Obtaining Low and Medium Molecular Weight Polyphenols and Standardized Solid Fuel from Tree Wood or Bark. (US 20090077871 A1, March 2009), (2009).

[12] M.T. Reijonen, A Method for the Production of Pine Bark Extract to Be Used as a Pharmaceutical, Herbal or Cosmetic Ingredient, by Using a Magnesium Compound. (WO 2015/055889 Al, October 2013), (2013).

[13] R. Soto, J. Freer, J. Baeza, Evidence of chemical reactions between di- and polyglycidyl ether resins and tannins isolated from Pinus radiata D. Don bark, Bioresour. Technol. 96 (2005) 95-101, https://doi.org/10.1016/j.biortech.2003.05.006.

[14] D.E. García, C.A. Fuentealba, J.P. Salazar, M.A. Pérez, D. Escobar, A. Pizzi, Mild hydroxypropylation of polyflavonoids obtained under pilot-plant scale, Ind. Crop. Prod. 87 (2016) 350-362, https://doi.org/10.1016/j.indcrop.2016.04.034.

[15] M. Jerez, J. Sineiro, E. Guitián, M.J. Núñe, Identification of polymeric procyanidins from pine bark by mass spectrometry, Rapid Commun. Mass Spectrom. 23 (2009) 4013-4018, https://doi.org/10.1002/rcm.4342.
[16] C.S. Ku, S.P. Mun, Characterization of proanthocyanidin in hot water extract isolated from Pinus radiata bark, Wood Sci. Technol. 41 (2007) 235-247, https://doi. org/10.1007/s00226-006-0103-8.

[17] C. Bocalandro, V. Sanhueza, A.M. Gómez-Caravaca, J. González-álvarez, K. Fernández, M. Roeckel, M.T. Rodríguez-Estrada, Comparison of the composition of Pinus radiata bark extracts obtained at bench- and pilot-scales, Ind. Crops Prod. 38 (2012) 21-26, https://doi.org/10.1016/j.indcrop.2012.01.001.

[18] E. Faure, C. Falentin-Daudré, C. Jérôme, J. Lyskawa, D. Fournier, P. Woisel, C. Detrembleur, Catechols as versatile platforms in polymer chemistry, Prog. Polym. Sci. 38 (2013) 236-270, https://doi.org/10.1016/j.progpolymsci.2012.06.004.

[19] Y. Lee, T.G. Park, Facile fabrication of branched gold nanoparticles by reductive hydroxyphenol derivatives, Langmuir 27 (2011) 2965-2971, https://doi.org/10. 1021/la1044078.

[20] Y.J. Oh, C.J. Jeong, S.M. Sharker, S.Y. Lee, I. In, S.Y. Park, Synthesis and antibacterial activity of versatile substrate-coated biocidal material via catechol chemistry, Surf. Interface Anal. 47 (2015) 259-264, https://doi.org/10.1002/sia. 5700 .

[21] H. Han, J. Wu, C.W. Avery, M. Mizutani, X. Jiang, M. Kamigaito, Z. Chen, C. Xi, K. Kuroda, Immobilization of amphiphilic polycations by catechol functionality for antimicrobial coatings, Langmuir 27 (2011) 4010-4019, https://doi.org/10.1021/ la1046904.

[22] P.A. Case, C. Bizama, C. Segura, M. Clayton Wheeler, A. Berg, W.J. DeSisto, Pyrolysis of pre-treated tannins obtained from radiata pine bark, J. Anal. Appl. Pyrolysis 107 (2014) 250-255, https://doi.org/10.1016/j.jaap.2014.03.009.

[23] S. Ohara, Y. Yasuta, H. Ohi, Structure elucidation of condensed tannins from barks by pyrolysis/gas chromatography, Holzforschung 57 (2003) 145-149, https://doi. org/10.1515/HF.2003.023.

[24] D.J. Nowakowski, A.V. Bridgwater, D.C. Elliott, D. Meier, P. de Wild, Lignin fast pyrolysis: results from an international collaboration, J. Anal. Appl. Pyrolysis 88 (2010) 53-72, https://doi.org/10.1016/j.jaap.2010.02.009.

[25] A. Berg, C. Fuentealba, J.P. Salazar, Separation of lignocellulosic components in acetic acid media and evaluation of applications, J. Sci. Technol. For. Prod. Process. 3 (2013) 27-32.

[26] J. Matos, C. Nahas, L. Rojas, M. Rosales, Synthesis and characterization of activated carbon from sawdust of Algarroba wood. 1. Physical activation and pyrolysis, J. Hazard. Mater. 196 (2011) 360-369, https://doi.org/10.1016/j.jhazmat.2011.09. 046.

[27] Q. Lu, X. Ye, Z. Zhang, C. Dong, Y. Zhang, Catalytic fast pyrolysis of cellulose and biomass to produce levoglucosenone using magnetic SO42-/TiO2-Fe3O4, Bioresour. Technol. 171 (2014) 10-15, https://doi.org/10.1016/j.biortech.2014. 08.075 .

[28] A. Oasmaa, E. Kuoppala, S. Gust, Y. Solantausta, Fast pyrolysis of forestry residue. 1. Effect of extractives on phase separation of pyrolysis liquids, Energy Fuels 17 (2003) 1-12, https://doi.org/10.1021/ef020088x.

[29] A. Moore, S. Park, C. Segura, M. Carrier, Fast pyrolysis of lignin-coated radiata pine, J. Anal. Appl. Pyrolysis 115 (2015) 203-213, https://doi.org/10.1016/j.jaap.2015. 07.017.

[30] D.S. Scott, P. Majerski, J. Piskorz, D. Radlein, A second look at fast pyrolysis of biomass-the RTI process, J. Anal. Appl. Pyrolysis 51 (1999) 23-37, https://doi. org/10.1016/S0165-2370(99)00006-6.

[31] N. Müller, R. Romero, H. Grandón, C. Segura, Selective production of formic acid by wet oxidation of aqueous-phase bio-oil, Energy Fuels 30 (2016) 10417-10424, https://doi.org/10.1021/acs.energyfuels.6b01345.

[32] V. Arpiainen, M. Lappi, Products from the flash pyrolysis, J. Anal. Appl. Pyrolysis 16 (1989) 355-376, https://doi.org/10.1016/0165-2370(89)80018-X.

[33] J. Kaal, K.G.J. Nierop, P. Kraal, C.M. Preston, A first step towards identification of tannin-derived black carbon: Conventional pyrolysis (Py-GC-MS) and thermally assisted hydrolysis and methylation (THM-GC-MS) of charred condensed tannins, Org. Geochem. 47 (2012) 99-108, https://doi.org/10.1016/j.orggeochem.2012.03. 009.

[34] M. Gaugler, W.J. Grigsby, Thermal degradation of condensed tannins from radiata pine bark, J. Wood Chem. Technol. 29 (2009) 305-321, https://doi.org/10.1080/ 02773810903165671.

[35] J. Cao, G. Xiao, X. Xu, D. Shen, B. Jin, Study on carbonization of lignin by TG-FTIR and high-temperature carbonization reactor, Fuel Process. Technol. 106 (2013) 41-47, https://doi.org/10.1016/j.fuproc.2012.06.016.

[36] T. Larraín, M. Carrier, L.R. Radovic, Structure-reactivity relationship in pyrolysis of plastics: a comparison with natural polymers, J. Anal. Appl. Pyrolysis 126 (2017) 346-356, https://doi.org/10.1016/j.jaap.2017.05.011.

[37] D.K. Shen, S. Gu, The mechanism for thermal decomposition of cellulose and its main products, Bioresour. Technol. 100 (2009) 6496-6504, https://doi.org/10. 1016/j.biortech.2009.06.095.

[38] S. Lomnicki, H. Truong, B. Dellinger, Mechanisms of product formation from the pyrolytic thermal degradation of catechol, Chemosphere 73 (2008) 629-633, https://doi.org/10.1016/j.chemosphere.2008.03.064.

[39] S. Zhan, W. Chenguang, B. Kang, Z. Xinghua, Y. Chiling, D. Renjie, M. Longlong, P. Changle, Py-GC/MS study of lignin pyrolysis and effect of catalysts on product distribution, Int. J. Agric. Biol. Eng. 10 (2017) 214-225, https://doi.org/10.25165/ j.ijabe.20171005.2852.

[40] M. Asmadi, H. Kawamoto, S. Saka, Thermal reactivities of catechols/pyrogallols and cresols/xylenols as lignin pyrolysis intermediates, J. Anal. Appl. Pyrolysis 92 (2011) 76-87, https://doi.org/10.1016/j.jaap.2011.04.012.

[41] F.X. Collard, J. Blin, A review on pyrolysis of biomass constituents: mechanisms and composition of the products obtained from the conversion of cellulose, hemicelluloses and lignin, Renew. Sustain. Energy Rev. 38 (2014) 594-608, https://doi. org/10.1016/j.rser.2014.06.013. 
[42] K.G.J. Nierop, C.M. Preston, J. Kaal, Thermally assisted hydrolysis and methylation of purified tannins from plants, Anal. Chem. 77 (2005) 5604-5614, https://doi.org/ 10.1021/ac050564r.

[43] S. Kubo, J.F. Kadla, Hydrogen bonding in lignin: a fourier transform infrared model compound study, Biomacromolecules 6 (2005) 2815-2821, https://doi.org/10. 1021/bm050288q.

[44] Z. Guo, S. Wang, Y. Gu, G. Xu, X. Li, Z. Luo, Separation characteristics of biomass pyrolysis oil in molecular distillation, Sep. Purif. Technol. 76 (2010) 52-57, https:// doi.org/10.1016/j.seppur.2010.09.019.

[45] B. Shrestha, Y. Brech, T. Ghislain, S. Hoppe, P. Marchal, S. Pontvianne, N. Brosse, V. Carré, F. Aubriet, A. Dufour, A multitechnique characterization of lignin softening and pyrolysis, ACS Sustain. Chem. Eng. 5 (2017) 6940-6949, https://doi.org/ 10.1021/acssuschemeng.7b01130.

[46] J. Meng, A. Moore, D. Tilotta, S. Kelley, S. Park, Toward understanding of bio-oil aging: accelerated aging of bio-oil fractions, ACS Sustain. Chem. Eng. 2 (2014) 2011-2018, https://doi.org/10.1021/sc500223e. 